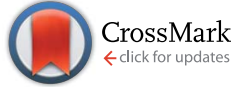

Cite this: Sustainable Energy Fuels, 2017, 1, 362

\title{
Digital imaging to simultaneously study device lifetimes of multiple dye-sensitized solar cells $\uparrow$
}

\author{
Leo Furnell, ${ }^{a}$ Peter J. Holliman, ${ }^{* a}$ Arthur Connell, ${ }^{a}$ Eurig W. Jones, ${ }^{a}$ Robert Hobbs, ${ }^{a}$ \\ Christopher P. Kershaw, ${ }^{a}$ Rosie Anthony, ${ }^{a}$ Justin Searle, ${ }^{b}$ Trystan Watson ${ }^{b}$ \\ and James McGettrick ${ }^{\mathrm{b}}$
}

In situ degradation of multiple dyes (D35, N719, SQ1 and SQ2) has been investigated simultaneously using digital imaging and colour analysis. The approach has been used to study the air stability of N719 and squaraine dyes adsorbed onto $\mathrm{TiO}_{2}$ films with the data suggesting this method could be used as a rapid screening technique for DSC dyes and other solar cell components. Full DSC devices have then been tested using either D35 or N719 dyes and these data have been correlated with UV-vis, IR and XPS spectroscopy, mass spectrometry, TLC and DSC device performance. Using this method, up to 21 samples have been tested simultaneously ensuring consistent sample exposure. Liquid electrolyte DSC devices have been tested under light soaking including the first report of D35 testing with $\mathrm{I}^{-} / \mathrm{I}_{3}^{-}$ electrolyte whilst operating at open circuit, short circuit, or under load, with the slowest degradation shown at open circuit. D35 lifetime data suggest that this dye degrades after ca. $370 \mathrm{~h}$ light soaking regardless of UV filtering. Control, N719 devices have also been light soaked for $2500 \mathrm{~h}$ to verify the imaging method and the N719 device data confirm that UV filtration is essential to protect the dye and $\mathrm{I}_{3}{ }^{-} / \mathrm{I}^{-}$electrolyte redox couple to maintain device lifetime. The data show a direct link between the colour intensity and/or hue of device sub-components and device degradation, enabling "real time" diagnosis of device failure mechanisms.

Received 10th January 2017

Accepted 13th January 2017

DOI: $10.1039 / \mathrm{c} 7 \mathrm{se} 00015 \mathrm{~d}$

rsc.li/sustainable-energy
Despite its importance for the commercialisation of $\mathrm{PV}$ technology, prior work on DSC device stability is limited given the large DSC literature. Those reports which do exist have typically focussed on small numbers of devices of one dye rather than comparative testing of multiple devices. This makes comparing literature reports difficult because testing parameters differ whilst any variance can be exacerbated by lengthy testing periods. Of the dyes tested in the literature, very different responses have been reported for dyes with different molecular structures suggesting this is a key factor affecting dye lifetime. For instance, Sommeling et al. carried out lifetime studies $(<1500 \mathrm{~h})$ for the Ru-bipyridyl dye N719 in DSC devices at open circuit exposed to light and/or reporting that ambient light soaking had the least effect on device performance but that exposure to 1 Sun at $85{ }^{\circ} \mathrm{C}$ caused the greatest losses. These losses were accompanied by electrolyte bleaching due to loss of $\mathrm{I}_{2}$. Xue et al. have also studied N719 degradation using UV-vis and Raman spectroscopy whilst DSC devices were studied using $I V$, IPCE and EIS data. ${ }^{13}$ The data showed a $20 \%$ drop in efficiency after $1074 \mathrm{~h}$ UV-filtered Xe-lamp light exposure. ${ }^{13}$ This study concluded that N719 degradation was the main reason for the drop in device performance. N719 has also been tested under Xe-lamps and thermal cycles by Giustini et al. ${ }^{14}$ whilst Bessho et al..$^{15}$ have extended Ru-bipy dye lifetime by replacing the vulnerable $\mathrm{NCS}^{-}$ligands achieving $\eta=10.1 \%$. The effect of
${ }^{a}$ School of Chemistry, Bangor University, Gwynedd LL57 2UW, UK. E-mail: p.j. holliman@bangor.ac.uk; Fax: +44 (0)1248 370528; Tel: +44 (0)1248 382375 ${ }^{b}$ SPECIFIC, College of Engineering, Swansea University, Baglan IKC, Port Talbot, SA12 $7 A Z U K$

$\dagger$ Electronic supplementary information (ESI) available. See DOI: $10.1039 / \mathrm{c} 7 \mathrm{se} 00015 \mathrm{~d}$ 
electrolyte bleaching with Z907 has been studied by Mastroianni et al., which showed image analysis could be used successfully to monitor the progress of electrolyte bleaching. ${ }^{\mathbf{1 6}}$

Organic DSC dye development has also been increasingly studied in recent times including indoline, ${ }^{17}$ half-squaraine ${ }^{18,19}$ and triphenylamine-based (TPA) dyes. ${ }^{20,21}$ To date, less has been reported on organic dye lifetimes although we have previously reported a TPA dye with $>1000 \mathrm{~h}$ stability ${ }^{21}$ with an $\mathrm{I}_{3}{ }^{-} / \mathrm{I}^{-}$redox couple and Joly et al. have also recently reported a TPA dye with high stability after $2200 \mathrm{~h}$ light soaking at $65{ }^{\circ} \mathrm{C}$ when using $\mathrm{I}_{3}{ }^{-} / \mathrm{I}^{-}$in an ionic liquid electrolyte. ${ }^{22}$ In addition, Tanaka et al. have suggested that decarboxylation of the cyanoacrylic acid linker of D131 is an important degradation mechanism for that dye and that electrolytes containing $\mathrm{I}_{2}$ and amine accelerate this. ${ }^{23}$ There has also been one recent report of D35 lifetime testing using $\mathrm{Co}(\mathrm{II} / \mathrm{III})$ redox couple which reports the influence of cation co-additives on dye photo-degradation. ${ }^{24}$

In recent years, the need to harvest longer wavelength photons has led to interest in squaraine dyes with several examples, e.g. SQ1 (ref. 25) and SQ2 (ref. 26) showing promise both as infrared harvesting dyes and also when co-sensitized with N719. ${ }^{27}$ For squaraine dyes, Paek et al. have reported panchromatic triphenylamine-modified squaraines with $1000 \mathrm{~h}$ stability under light soaking at $60{ }^{\circ} \mathrm{C},{ }^{28}$ whilst Qin et al. have reported $1000 \mathrm{~h}$ stability for double linker squaraines using an ionic liquid electrolyte. ${ }^{29}$ In addition, Wu et al. have studied squaraine dye degradation under visible light demonstrating that $\mathrm{TiO}_{2}$ acts as a photo-catalyst for this by cleaving the $\mathrm{C}=\mathrm{C}$ double bond in the dye. ${ }^{30}$ In this context, the photocatalytic activity of $\mathrm{TiO}_{2}$ is well known ${ }^{31}$ and has been studied for water purification and waste degradation. ${ }^{32}$

Currently, there is a range of dyes which absorb across the visible spectrum. Whilst clearly there is still a need to optimise dye combinations to enhance light harvesting, there is also a need to understand much more about the lifetimes of dyes which absorb from 400-900 nm and under "real-life" working conditions. An image analysis method developed by Asghar et $a l .{ }^{33}$ has been built upon to directly compare multiple dyed samples or devices under the same exposure conditions. As such, this paper reports the use of digital photography and colour image analysis to quantify real time dye degradation to study failure mechanisms of dye adsorbed on $\mathrm{TiO}_{2}$ and in full DSC devices. We have chosen red and blue dyes to study DSC dye lifetimes across a wide range of $\lambda$ in one paper. These dyes have been tested under a range of device operating conditions (i.e. at open circuit, short circuit or under a $10 \Omega$ load) allowing a detailed picture of device lifetime to be formed.

\section{Experimental}

\section{Dye choice and sample preparation}

The dyes chosen include the triphenylamine dye (D35, Dyenamo) which has previously been reported in DSC devices and has proved effective both for co-sensitisation ${ }^{34}$ and in solid state devices $^{35}$ (Scheme 1). However, to the best of our knowledge there are no literature reports of D35 stability testing using $\mathrm{I}^{-} / \mathrm{I}_{3}{ }^{-}$electrolyte. N719 (Dyesol) has been chosen to act as

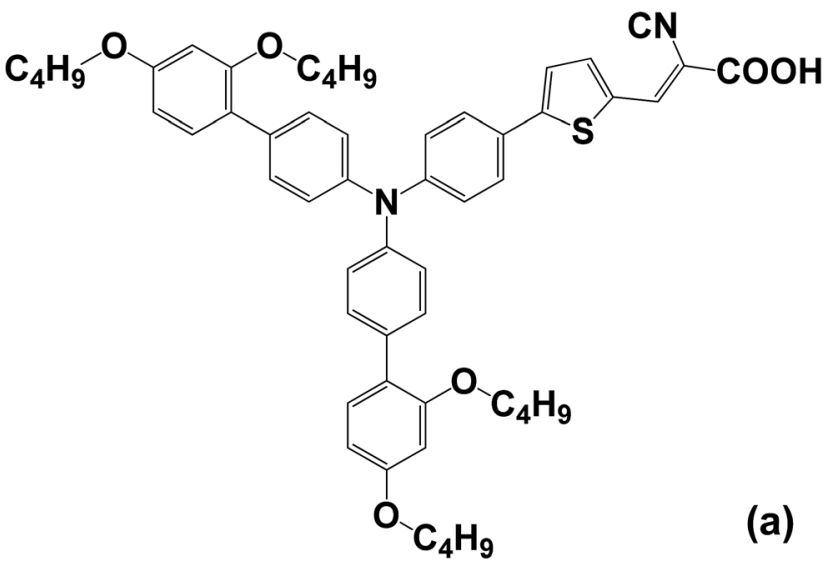

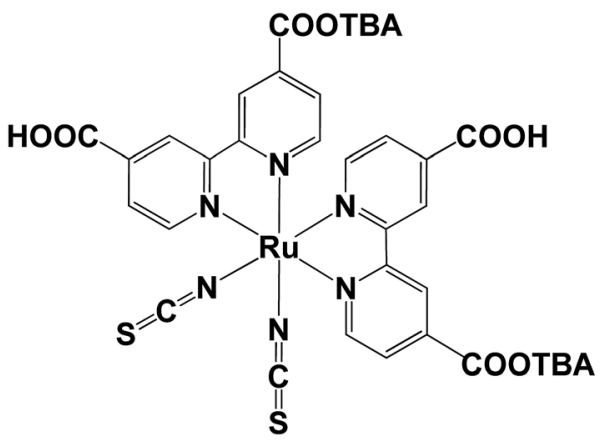

(b)<smiles>CCN1/C(=C\C2=C([O-])C(=CC3=[N+]([12F])c4ccc(C(=O)O)cc4C3(C)C)C2=O)C(C)(C)c2ccccc21</smiles>

(c)

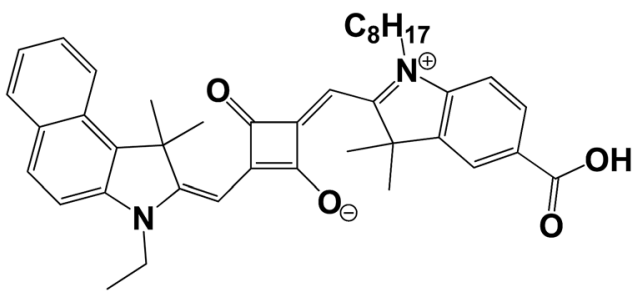

(d)

Scheme 1 Molecular structures of (a) the triphenylamine dye D35, (b) ruthenium bipyridyl dye N719 and (c) and (d) the squaraine dyes SQ1 and SQ2, respectively.

control dye as it has been widely studied along with the squaraine dyes SQ1 (prepared in house according to Burke et $a .^{25}$ ) and SQ2 (Solaronix) which are known to be susceptible to degradation in air (Scheme 1).

\section{Dye-TiO ${ }_{2}$ testing}

A Photosimile 200 light box was used to simultaneously study the dye degradation of multiple dye samples adsorbed onto $\mathrm{TiO}_{2}$ films under constant artificial light as this had sufficient floor space $(40.8 \times 58.7 \mathrm{~cm})$, consistent light intensity $\left(5 \mathrm{~W} \mathrm{~m}^{-2}\right.$, 
6000 lux) and an in-built slot for a camera to be placed directly above the samples. A Canon EOS 1100D with an 18-55 VR lens was used to take pictures at regular intervals ranging from 1 to 5 s. Samples were placed on a numbered grid with a white background (Fig. 1) alongside 2 contrast controls; an undyed $\mathrm{TiO}_{2}$ film to give $100 \%$ "white" and a black square to give $100 \%$ "black". A clock was also added to verify that the time-lapse images were being taken at the correct time intervals. It was important to align the films consistently because a macro within the computer software (Sigma Scan Pro 5) was used to select and analyse red, green, blue (RGB) intensities at fixed points on each film. The macro also analysed the control films to adjust for any changes in the light levels whilst the black control ensured consistent camera focus during any colour change within the $\mathrm{TiO}_{2}$ films.

Dye- $\mathrm{TiO}_{2}$ exposure samples were prepared as follows. TEC15 glass $(1.5 \times 3 \mathrm{~cm}, \mathrm{NSG})$ was cleaned by sonicating in acetone before drying with $\mathrm{N}_{2}$. One layer of $\mathrm{P} 25 \mathrm{TiO}_{2}$ colloid paste was doctor bladed onto the glass using a single layer of Scotch ${ }^{\mathrm{TM}}$ tape as a spacer before sintering at $500{ }^{\circ} \mathrm{C}$. After cooling to $80{ }^{\circ} \mathrm{C}$, the $\mathrm{TiO}_{2}$ films (ca. $7 \mu \mathrm{m}$ thickness) were immersed in $0.5 \mathrm{mM}$ ethanolic dye solution of SQ1, SQ2 or N719 in ${ }^{t}$ butanol : $\mathrm{CH}_{3} \mathrm{CN}(1: 1 \mathrm{v} / \mathrm{v})$ for $18 \mathrm{~h}$ before rinsing with ethanol and drying under $\mathrm{N}_{2}$.

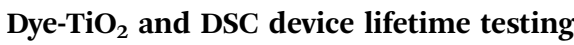

$\mathrm{TiO}_{2}$ DSC device photo-anodes were prepared in the same way as for the dye- $\mathrm{TiO}_{2}$ exposure samples except that the films were prepared using one layer of active opaque colloid (AO, Dyesol). Platinum paste (PT-1, Dyesol) was deposited onto pre-drilled counter electrodes and sintered at $400{ }^{\circ} \mathrm{C}$. The 2 electrodes were sealed together with Surlyn $(25 \mu \mathrm{m})$ at $120{ }^{\circ} \mathrm{C}$ to produce $1 \mathrm{~cm}^{2}$ devices and electrolyte was injected. N719 and D35 electrolytes were prepared in $\mathrm{CH}_{3} \mathrm{CN}$ containing $\mathrm{I}_{2}(0.05 \mathrm{M})$ and guanidinium thiocyanate $(0.05 \mathrm{M})$. For $\mathrm{D} 35,{ }^{t} \mathrm{Bu}_{4} \mathrm{NI}(0.6 \mathrm{M})$, LiI $(0.1 \mathrm{M})$ and $4{ }^{t}{ }^{t} \mathrm{Bu}$ pyridine $(0.5 \mathrm{M})$ were added. ${ }^{34}$ For N719, 1-methyl3-propylimidazolium iodide $(0.8 \mathrm{mM})$ and benzimidazole (0.3 mM) were added.

DSC devices were light soaked in a Photosimile 200 light box which had been stabilised for $2 \mathrm{~h}$ before use (ESI Fig. 1 and $2 \dagger$ ). Digital images were taken every $20 \mathrm{~s}$ using a Canon EOS 1100D camera with an 18-55 mm lens. Image analysis was carried out using a custom-built macro, which analysed each film individually. ${ }^{36}$ Devices were studied using image analysis and $I V$ testing under standard conditions (1 Sun, AM1.5). After light soaking, selected device electrodes were separated and analysed (UV-vis, ATR-IR, MS, XPS). Other devices that were left sealed had the electrolyte removed and replaced or had the dye desorbed with $0.1 \mathrm{M}^{t} \mathrm{Bu}_{4} \mathrm{NOH}$ before the device cavity neutralized with $2 \mathrm{M}$ $\mathrm{HCl}_{(\mathrm{aq})}$ and re-dyed according to Holliman et al. ${ }^{37}$

\section{Results and discussion}

\section{Lifetimes of $\mathrm{TiO}_{2}$-sorbed dyes}

The lifetimes of two squaraine DSC dyes (SQ1 and SQ2), the Ru-bipy DSC dye N719 the triphenylamine DSC dye (D35)

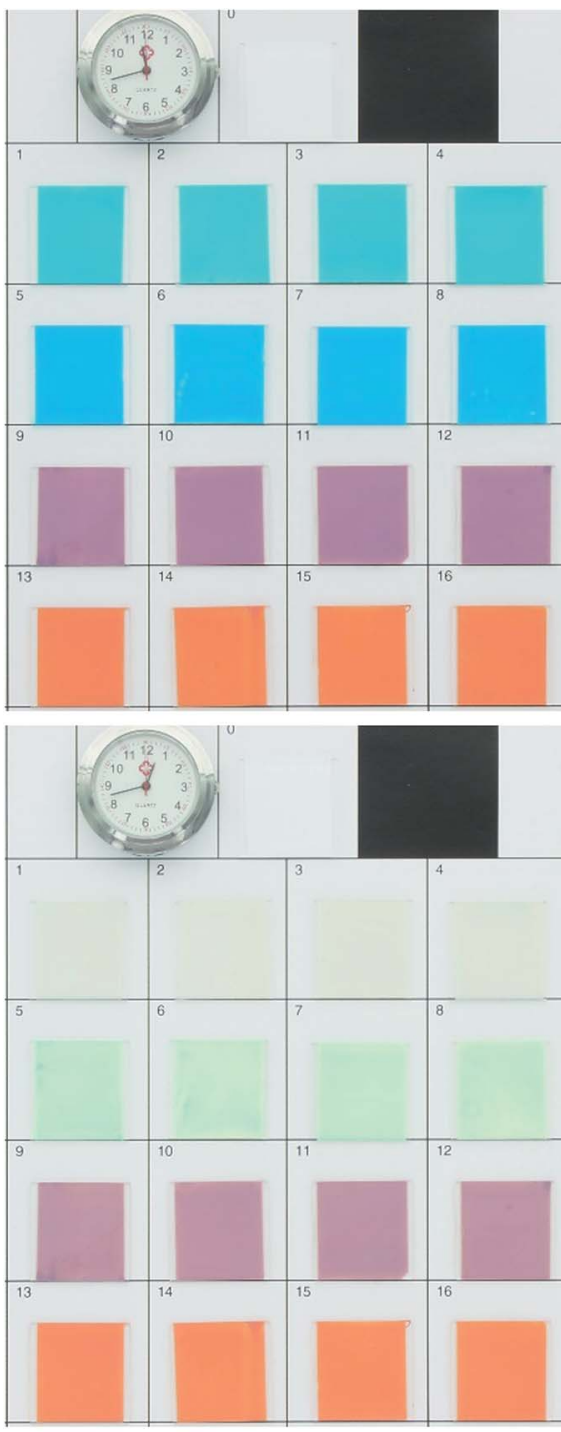

(a)

(b)

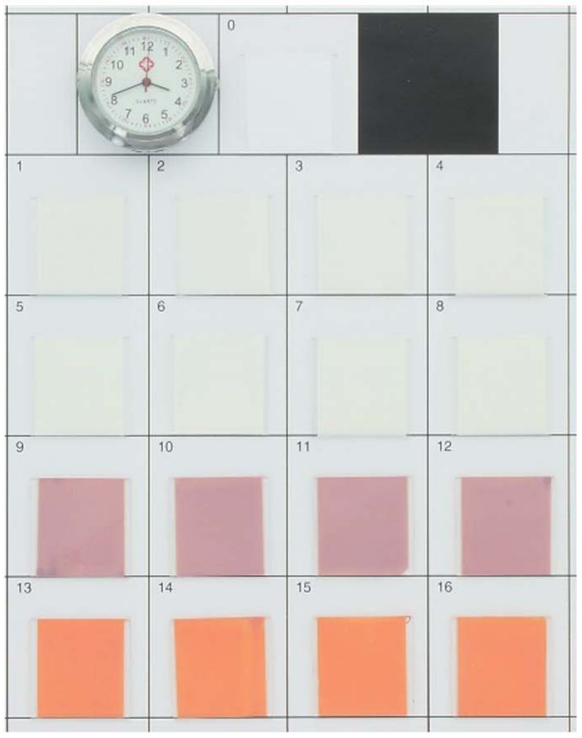

(c)

Fig. 1 Digital image of the grid layout for the lifetime studies of dyed $2 \times 2 \mathrm{~cm} \mathrm{TiO}_{2}$ films (a) as dyed before light exposure, and after (b) $1 \mathrm{~h}$ and (c) $4 \mathrm{~h}$ light exposure. Controls were an undyed $\mathrm{TiO}_{2}$ film (top centre, position 0) next to a black square. Top row $=S Q 1,2^{\text {nd }}$ row $=$ $\mathrm{SQ} 2,3^{\text {rd }}$ row $=\mathrm{N} 719$ and bottom row $=$ D35. 
adsorbed on P25 $\mathrm{TiO}_{2}$ films have been simultaneously exposed to the same light and atmospheric conditions for $4 \mathrm{~h}$ and the digital images are shown in Fig. 1 and the RGB intensity data in Fig. 2. The aim of this experiment was to test whether atmospheric light exposure of dyes adsorbed to mesoporous $\mathrm{TiO}_{2}$ films can be used as a rapid, simple means to screen DSC dye lifetimes.

Looking first at the adsorbed SQ1 dye, this shows the fastest rate of bleaching (Fig. 2a) degradation of adsorbed SQ1. When analysing the RGB data, it is important to note that, for a bluegreen dye like SQ1, most of the red components will be absorbed whilst the blue and green components will be strongly reflected. This can be seen in the initial RGB values (ca. 200) for blue and green for SQ1 whilst the red value is $c a$. 70. The rapid bleaching of SQ1 can then be seen in the RGB data by the exponential drop in the signal from the red component which, as the complimentary colour to blue, corresponds to a reduction in the blue colour of the dye. Thus, after $2 \mathrm{~h}$, the red colour has reached a value of 200 , which is similar to the blue and green values (which change very little during the measurements on this dye). Hence, after $2 \mathrm{~h}$, these films are effectively deemed colourless by this technique (confirmed by visual inspection of Fig. 1b). The rapid discolouration of $\mathrm{TiO}_{2}$-sorbed squaraine dyes in air has been reported previously. ${ }^{30}$ We have also observed this previously when making SQ1 dye-sensitized solar cells. In fact, only by using a sealed, pump dyeing system have we been able to manufacture squaraine DSC devices with high efficiency such is the rapidity of degradation. ${ }^{27}$ It should be noted here that the errors of the RGB analysis (ESI Fig. 3, ESI Table $1 \dagger$ ) show \pm 0.95 arbitrary units (a.u.) for red, \pm 0.59 a.u. for green and \pm 1.46 a.u. for blue. The higher error for blue is a result of fewer sensors in the camera for the colour blue. This is because camera sensors are designed to mimic human eyes, which have fewer cones to detect blue colour compared to red and green ones. ${ }^{38}$

SQ2 is also a blue-green dye. However, this dye shows a very different RGB profile over the $4 \mathrm{~h}$ test for (Fig. 2b) with a slower loss of the red intensity compared to SQ1 such that the red component only reaches a value of 200 after $c a .4 \mathrm{~h}$. This is interesting because SQ1 and SQ2 possess similar molecular structures with SQ2 possessing a naphthyl unit on one of the indole moieties compared to a benzene unit for SQ1 (Scheme 1). The naphthyl unit causes a red-shift on the SQ2 absorption by ca. $50 \mathrm{~nm}$ relative to SQ1 whilst SQ2 $\left(319000 \mathrm{dm}^{3} \mathrm{~mol}^{-1} \mathrm{~cm}^{-1}\right)$ also possesses a slightly higher $\varepsilon$ than SQ1 $292000 \mathrm{dm}^{3} \mathrm{~mol}^{-1}$ $\left.\mathrm{cm}^{-1}\right) .{ }^{26}$ For these two relatively unstable dyes, the absorption of lower energy photons and more intense dye colour seem more likely explanations for slower SQ2 degradation than any direct enhancement of chemical stability arising from SQ2's naphthyl unit. By comparison, N719 is a red-brown dye and so Fig. 2c shows that, initially, the blue and green components (RGB pixel values of 140 and 165, respectively) are absorbed more than the red which is relatively more reflected (RGB value of 180). Over the $4 \mathrm{~h}$ measurement, the pixel values for each of the RGB do not drop significantly and do not reach a value of 200 . This suggests that little bleaching of N719 takes place over $4 \mathrm{~h}$ and hence that N719 is a more stable dye than SQ1 or SQ2 under these conditions. This again is in line with previous reports of

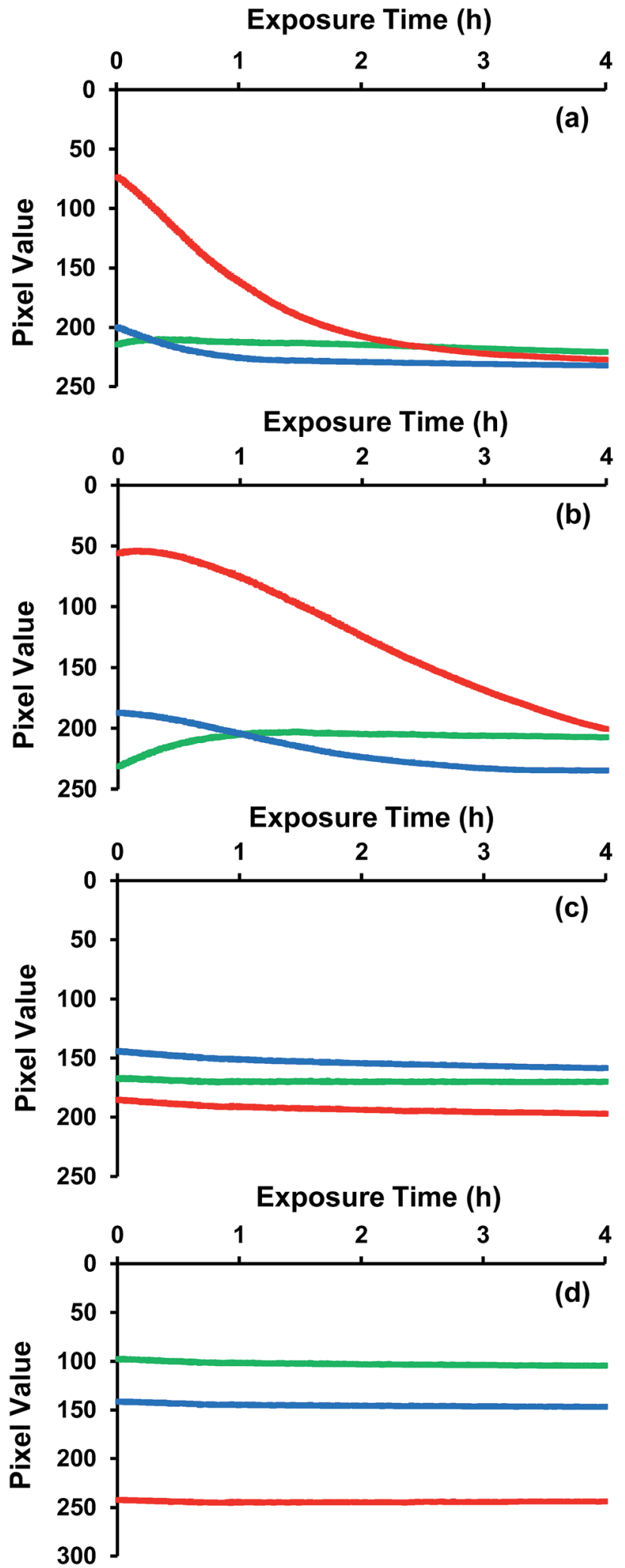

Fig. 2 Red, green, blue (RGB) pixel values for $\mathrm{TiO}_{2}$ films dyed with (a) SQ1 (b) SQ2 and (c) N719 and (d) D35 over 4 h exposure. N.B. when red, blue and green pixel values are all ca. 200, the electrode has faded fully. 
N719 stability testing. ${ }^{\mathbf{1 0 , 1 2 , 3 9 - 4 1}}$ The D35 data show initial RGB values of 190, 100 and 140, respectively which is line with this dye being red-orange rather than brown (Fig. 2d). These values remain unchanged over the $4 \mathrm{~h}$ test period suggesting that this dye is also stable under these exposure conditions. In addition, the control (undyed) $\mathrm{TiO}_{2}$ film was exposed and analysed in the same way (ESI Fig. $3 \dagger$ ). These data show that the $\mathrm{TiO}_{2}$ colour and light intensity remain stable for the duration of the test.

Looking at the data from the four dyes together, clear differences are observed in the rate of colour change between the dyes and these changes are in line with previous stability reports for these dyes in full DSC devices. This suggests that digital imaging and analysis of $\mathrm{TiO}_{2}$-sorbed dyes even over relatively short periods (i.e. $4 \mathrm{~h}$ ) can be used as a rapid screening method for DSC dye lifetime.

\section{DSC device lifetime testing}

Full DSC devices have also been tested using a combination of digital imaging and RGB analysis, $I-V$ testing and forensic analysis. For D35 devices, looking at the RGB data first, Fig. 3 shows that initial blue and green RGB values of $c a$. 60 in line with the absorption of these colours. However, the initial data show that the red component is relatively more reflected with a pixel value of $c a .100$ in line with the fact that D35 is a red dye. Then, between 0 and $150 \mathrm{~h}$, the blue and green components drop slightly whilst the $I V$ data show a slight increase in efficiency (Fig. 3a) which is ascribed to changes in dye:electrolyte interactions due to improved $\mathrm{TiO}_{2}$ pore filling as the devices age. Then, the blue and green pixel values remain fairly constant for the rest of the $660 \mathrm{~h}$ of testing. By comparison, the RGB data show a gradual change in the red component of the dye from 0 to $c a .370 \mathrm{~h}$ until it reaches a value similar to the blue and green components (i.e. ca. 60), after which it remains constant. This means the red component is being absorbed at a similar level to the blue and green components and the absorption of all colours of light means the sample has turned black which is confirmed by visual analysis (Fig. 3c). Overall, these data suggest that the dye has degraded over the $370 \mathrm{~h}$ time period. To study this further, light soaking was continued up to $660 \mathrm{~h}$ to fully degrade the devices (full data are shown in ESI Fig. 4-6, ESI Table $2 \dagger$ ).

The RGB data correlate closely with the $I-V$ data which show a substantial loss of $\eta$ between 0 and $370 \mathrm{~h}$ light exposure (Fig. 3a). The device testing parameters $\left(V_{\mathrm{oc}}, J_{\mathrm{sc}}, \mathrm{FF}\right.$ and $\eta$ ) are plotted against time in ESI Fig. 6a. $\uparrow$ These data show substantial drops in $J_{\mathrm{sc}}$ between 120 and $370 \mathrm{~h}$ which align closely with the drop in device efficiency over this time period. Whilst the drop in $J_{\mathrm{sc}}$ is slower for some unfiltered devices, these changes are consistent for all the devices tested up to $670 \mathrm{~h}$. By comparison, the $V_{\text {oc }}$ drops from $c a .0 .8 \mathrm{~V}$ which is observed for all devices between 0 and $120 \mathrm{~h}$ to $\mathrm{ca}$. $0.6 \mathrm{~V}$ after $370 \mathrm{~h}$ for all unfiltered devices. However, for some UV-filtered devices the $V_{\text {oc }}$ increases to $c a .1 .0 \mathrm{~V}$ after $370 \mathrm{~h}$ although it should be noted that the very small $J_{\text {sc }}$ for these devices means that they are not operating normally by this stage. After $660 \mathrm{~h}$ of testing the $V_{\text {oc }}$ appears quite random between 0.2 and $1.5 \mathrm{~V}$. However, the very low

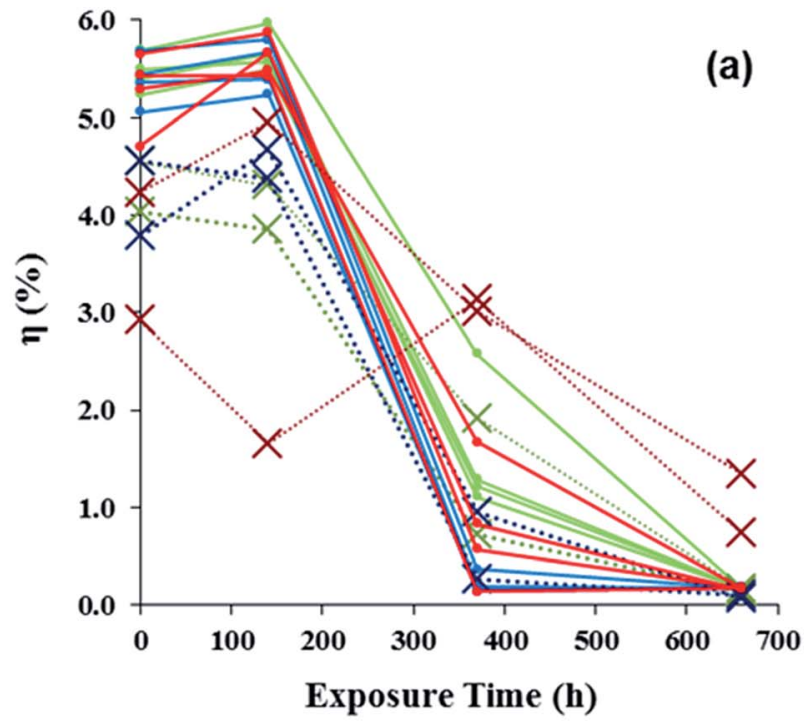

Exposure Time (h)

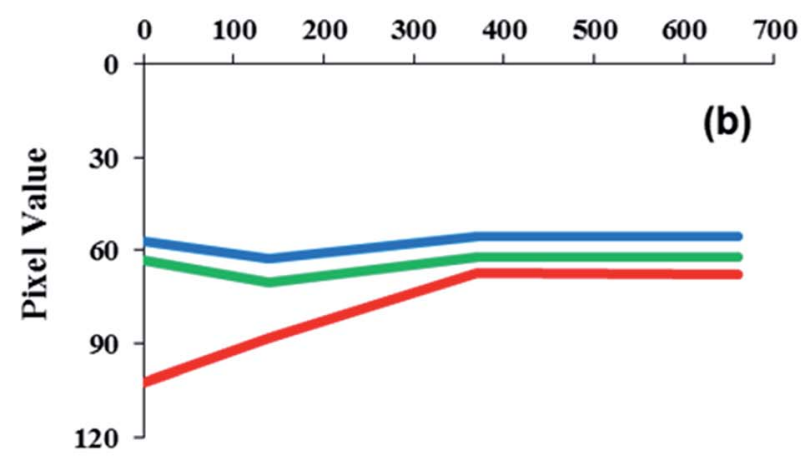

(c)

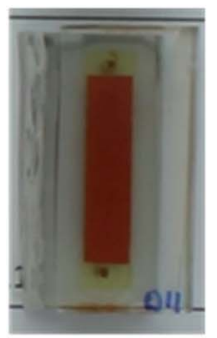

(i)

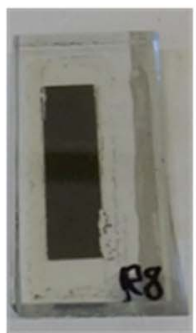

(ii)

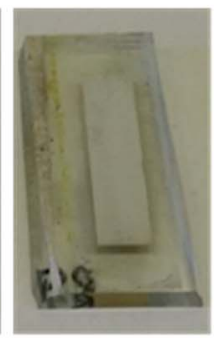

(iii)

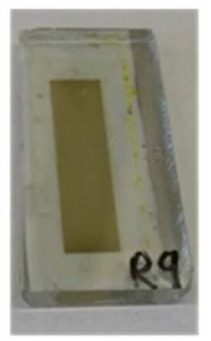

(iv)
Fig. 3 D35 device lifetime data; (a) $\eta$ vs. time under $400 \mathrm{~W} \mathrm{~m}^{-2}$ lightsoaking with (solid lines $\&$ circles) or without (dashed lines \& crosses) a UV-filter. Devices were under a $10 \Omega$ load (red lines) or at open (blue lines) or short circuit (green lines); (b) RGB pixel intensity data vs. time for electrolyte colour without a UV filter and (c) images of D35-dyed $\mathrm{TiO}_{2}$ at $\mathrm{O}$ h (i), after $330 \mathrm{~h}$ light soaking (ii), front of desorbed $\mathrm{TiO}_{2}$ electrode (iii) and back of desorbed $\mathrm{TiO}_{2}$ electrode (iv).

performance of the devices by this time makes accurate $I V$ measurements quite difficult. The FF data reflect this by showing an increasing spread on the data with time. Broadly, the FF values for the UV-filtered devices increase with time until the values exceed 1.0, which is the theoretical maximum. Hence, whilst data for $\mathrm{FF}>1.0$ are not real there is an 
interesting, opposing trend for UV-unfiltered data which drop to between 0.2 to 0.6 which suggest that the electrolyte may also be being photo-oxidized by UV with time as has been reported previously for other dyes. ${ }^{42}$ Values for the series and shunt resistance data for the devices over time have also been calculated (ESI Fig. 6b†). Initially the devices show shunt resistances $\left(R_{\mathrm{sh}}\right)$ of 1.0 to $5.0 \mathrm{k} \Omega$ and series resistances $\left(R_{\mathrm{S}}\right)$ of 17 to $40 \Omega$. Both the $R_{\mathrm{sh}}$ and $R_{\mathrm{S}}$ data start to increase between 120 and $370 \mathrm{~h}$ in line with the device performance dropping with the $R_{\mathrm{S}}$ increasing to $\infty$ for all but one condition (UV-unfiltered under load). For an ideal photo-diode, $R_{\mathrm{sh}}=\infty$ whilst $R_{\mathrm{s}}=0$ because $R_{\mathrm{S}}$ corresponds to the sum of all the device resistance elements. ${ }^{43}$ Here, the increase in $R_{\mathrm{s}}$ to $\infty$ suggests a complete breakdown of one or more components in the devices.

After testing for $660 \mathrm{~h}$, the devices were split into 2 batches for detailed analysis of the device failure mechanisms. For the first batch, the aim was to study whether the devices could be regenerated by replacing each device component in a step-wise manner. For the second group of devices, the 2 electrodes were separated and detailed analysis carried out on the different device components. Looking at the first batch of devices, the first test was to remove the existing electrolyte, wash the device cavity and to add fresh electrolyte. Table 1 shows the $J_{\text {sc }}$ remained the same after new electrolyte had been added which shows that significant dye degradation had occurred during light soaking which substantially limits light harvesting. By comparison, the FF improved slightly from 0.34 to 0.45 when fresh electrolyte was added implying that, whilst some electrolyte degradation had taken place during light soaking, this was reversible when new $\mathrm{I}_{3}{ }^{-} / \mathrm{I}^{-}$redox couple was applied. The next device sub-component tested was the D35 dye. Fig. 3c shows the colour change of D35 from the initial red colour (i) to brown after light soaking (ii). This is confirmed by DRUV-vis spectroscopy (ESI Fig. $7 \dagger$ ) which shows a peak centred at ca. $480 \mathrm{~nm}$ for adsorbed D35 which weakens in intensity and broadens after light soaking (ESI Fig. 7c $\dagger$ ). The dye was then desorbed using ${ }^{t} \mathrm{Bu}_{4} \mathrm{NOH}_{(\mathrm{aq})}$ and the desorbed solution was analysed by UV-vis spectroscopy showing almost complete disappearance of the D35 peak at ca. $450 \mathrm{~nm}$ indicating chromophore breakdown (ESI Fig. $8 \dagger$ ). For the desorbed $\mathrm{TiO}_{2}$, the counter electrode side of the photo-anode shows a white surface (Fig. 3c(iii)) which is confirmed by DRUV-vis spectroscopy (ESI Fig. 7d†). By comparison, the $\mathrm{TiO}_{2}$ photo-anode closest to the working electrode (i.e. the side directly exposed during light soaking) is light brown (Fig. 3c(iv)) which is ascribed to photo-degraded dye. This was tested by re-dyeing the photo-anode with
D35 dye. Table 1 shows a substantial improvement in device performance on re-dyeing with $J_{\mathrm{sc}}$ and $V_{\mathrm{oc}}$ increasing to $9.34 \mathrm{~mA} \mathrm{~cm}^{-2}$ and $0.66 \mathrm{~V}$ compared to $0.67 \mathrm{~mA} \mathrm{~cm}^{-2}$ and $0.28 \mathrm{~V}$ for the light soaked device. However, the $J_{\mathrm{sc}}$ and $V_{\mathrm{oc}}$ are lower than in the pre-light soaked devices and the fill factor remains very poor $(\mathrm{FF}=0.34)$. This is ascribed to surface organic matter from degraded dye blocking some dye sorption sites leading to lower $J_{\mathrm{sc}}$ as confirmed by ATR infrared spectroscopy (ESI Fig. 9d †). This organic matter is also believed to increase electron recombination which lowers $V_{\text {oc }}$ and increases series resistance by blocking charge transfer to the working electrode which, in turn, lowers FF. To test this, and if the reduced $J_{\mathrm{sc}}$ and brown colouration was due to degraded dye occupying dye sorption sites on the $\mathrm{TiO}_{2}$, the photo-anode was re-sintered at $450{ }^{\circ} \mathrm{C}$ and re-dyed. However, the data show that the efficiency did not increase $(\eta=1.4 \%)$. Instead, the $J_{\text {sc }}$ dropped slightly to $7.67 \mathrm{~mA} \mathrm{~cm}{ }^{-2}$ which may reflect that repeating the sintering step reduces $\mathrm{TiO}_{2}$ surface area. Unfortunately this would result in fewer dye sorption sites which hides any device improvement which might result from removing degraded dye. In fact, the biggest problem for this device is the low fill factor $(\mathrm{FF}=0.30)$ which is due to the loss of Pt from the counter electrode as shown by XPS analysis (ESI Table $3 \dagger$ ).

For the second batch of devices, the electrolyte was studied by UV-vis spectroscopy (ESI Fig. 10-12†) showing that UV filtered devices contained $53.0 \mathrm{mM} \mathrm{I}_{3}{ }^{-}$whilst devices without UV filtering contained $42.5 \mathrm{mM} \mathrm{I}_{3}{ }^{-}$. This confirmed the image analysis which suggested the electrolyte had not notably changed colour over $660 \mathrm{~h}$. This also confirmed that $\mathrm{I}_{3}{ }^{-}$loss is not the main reason for D35 device failure. D35 dye was then desorbed from the $\mathrm{TiO}_{2}$ and analysed by thin layer chromatography (TLC) and mass spectrometry (MS). TLC shows a significant change in $R_{\mathrm{f}}$ value for degraded D35 dye compared to pristine D35 (ESI Fig. 13†). This change is similar for D35 degraded with or without UV filtering, suggesting UV light does not affect the degradation pathway. From the MS data, whilst pristine D35 shows an intense molecular ion at ca. 861 amu in line with the literature, ${ }^{44}$ the aged and desorbed dyes show only a trace of molecular ion and a noticeable loss of higher mass fragments (ESI Fig. 14†). The predominant ion remaining is at ca. 392 amu which corresponds to the central moiety of the dye after the loss of phenyl ether units from the triphenylamine donor and the nitrile from the linker group. XPS has been used to study the surfaces of working and counter electrodes of D35 devices light soaked for $660 \mathrm{~h}$ which have either been ethanol washed or had the dye desorbed with ${ }^{t} \mathrm{BuN}_{4} \mathrm{OH}$ and

Table 1 IV data for a D35 DSC device light soaked at open circuit without UV filtering

\begin{tabular}{llllll}
\hline Device & FF & $\eta(\%)$ & $V_{\text {oc }}(\mathrm{V})$ & $J_{\text {sc }}\left(\mathrm{mA} \mathrm{cm}^{-2}\right)$ & $R_{\text {sh }}(\Omega)$ \\
\hline After 0 h & 0.52 & 4.7 & 0.82 & 10.87 & 3333 \\
After 600 h light soaking & 0.34 & 0.1 & 0.28 & 0.67 & 17 \\
After new electrolyte & 0.45 & 0.1 & 0.49 & 0.61 & 5000 \\
D35 dye desorbed & 0.28 & 0.0 & 0.10 & 0.57 & 2500 \\
Re-dyed with D35 & 0.34 & 2.1 & 0.66 & 143 \\
Re-sintered \& re-dyed & 0.30 & 1.4 & 0.61 & 7.67 & 130 \\
\end{tabular}


data correlated with the NIST database. ${ }^{45}$ As expected for $\mathrm{TiO}_{2}$ working electrodes (WE), the solvent washed and dye desorbed samples show Ti 2p signals at $458.3 \mathrm{eV}$ with levels of $20.1 \pm$ 0.6 at $\%$ and $22.9 \pm 0.8$ at\%, respectively. These samples also show O 1s peaks at $529.5 \mathrm{eV}$ and $530.8 \mathrm{eV}$ consistent with $\mathrm{TiO}_{2}$ and organic $\mathrm{O}$ environments. The increase in the Ti signal is mirrored for $\mathrm{O}$ which increases from $45.4 \pm 1.0$ at\% to $52.0 \pm$ 1.1 at\% which is in line with dye desorption freeing up $\mathrm{TiO}_{2}$ sorption sites. Both samples show a small N 1s signal. The peak at $399.5 \mathrm{eV}$ is ascribed to surface adsorbed ${ }^{t} \mathrm{Bu}$-pyridine observed on the solvent washed sample. ${ }^{46}$ After dye desorption, the nitrogen peak is shifted to $402.2 \mathrm{eV}$ which is more consistent with quaternary ammonium salts such as ${ }^{t} \mathrm{Bu}_{4} \mathrm{~N}^{+}$used as the base for dye desorption. The other major species is $\mathrm{C} 1 \mathrm{~s}$ at $284.8 \mathrm{eV}$ which drops from $33.9 \pm 1.4$ at $\%$ to $23.8 \pm 1.7 \%$ at $\%$ after dye desorption in line with dye removal from the $\mathrm{TiO}_{2}$ surface. For the counter electrodes (CE), a Sn 3d signal at $486.5 \mathrm{eV}$ is observed for the FTO substrate which drops from 15.7 to 6.6 at\% on dye desorption. Then two $\mathrm{O} 1 \mathrm{~s}$ signals are observed at ca. $532.0 \mathrm{eV}$ for $\mathrm{SnO}_{2}$ and organic $\mathrm{O}$ which drop from 35.8 to $27.5 \pm 6.2$ at\% on dye desorption. The high error reflects highly variable peak intensities. Platinum (Pt 4f, $70.5 \mathrm{eV}$ ) also drops from 5.6 to $1.8 \pm 0.3$ at $\%$ on base treatment. The other main signals are for organic $\mathrm{C}$ and $\mathrm{Na}$ with $1 \mathrm{~s}$ peaks at 284.8 and $401.8 \mathrm{eV}$, respectively. However, these signals increase on dye desorption; C from 36.0 to 55.4 at\% and $\mathrm{N}$ from 2.9 to $3.4 \pm 0.6$ at\%. These data can be explained by the action of the ${ }^{t} \mathrm{Bu}_{4} \mathrm{NOH}$ desorbing dye from the working electrode and redepositing this onto the $\mathrm{CE}$ as the base is pumped through the device cavity. At the same time, some Pt particles are removed while a number of ${ }^{t} \mathrm{Bu}_{4} \mathrm{~N}^{+}$ions adsorb to the $\mathrm{CE}$ surface. In summary, whilst the XPS clearly shows the changes which occur during dye desorption, the data suggest the WE and CE are not the main reason for the drop in device function. This still suggests that dye degradation is the main problem for D35 devices.

N719 devices were also studied as a control experiment to validate the digital imaging and analysis method by light soaking under a Dyesol UPTS lamp for $2500 \mathrm{~h}$ with regular $I-V$ device testing using a solar simulator to track degradation. As shown by the device efficiency data in Fig. 4a, without UV filtration, DSC device efficiency declines between 500 and 1000 h. The same devices were also digitally imaged (ESI Fig. 15-17†) and the RGB intensity data were analysed. These data show very little change in N719 colour for DSC devices regardless of whether they had a UV-filter or not. By comparison, the presence of a UV filter had a considerable influence on electrolyte colour. ESI Fig. 16b† shows a rapid loss of blue colour for the non UV-filtered devices up to $c a .700 \mathrm{~h}$ which is not observed when UV filter is in place (ESI Fig. 16c $\dagger$ ). The loss of electrolyte colour correlates strongly with the loss of device efficiency in UV-unfiltered devices. This confirms that digital imaging can be used as a method to study DSC device lifetimes. Looking at reasons for the drop in device performance, UV degradation of the electrolyte has previously been reported by Carnie et al. ${ }^{\mathbf{4 2}}$ who observed that iodine-based electrolytes are prone to failure after extended light exposure without UV filtration. Fig. 4a also
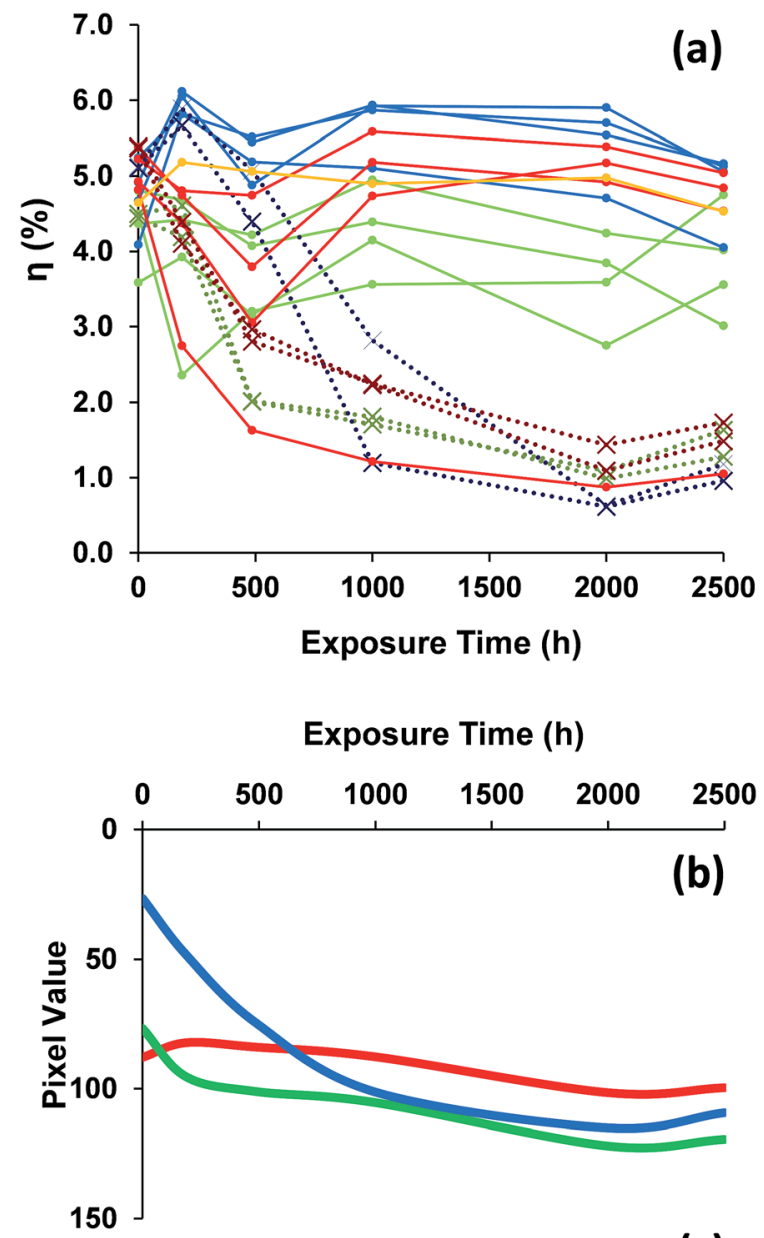

(c)

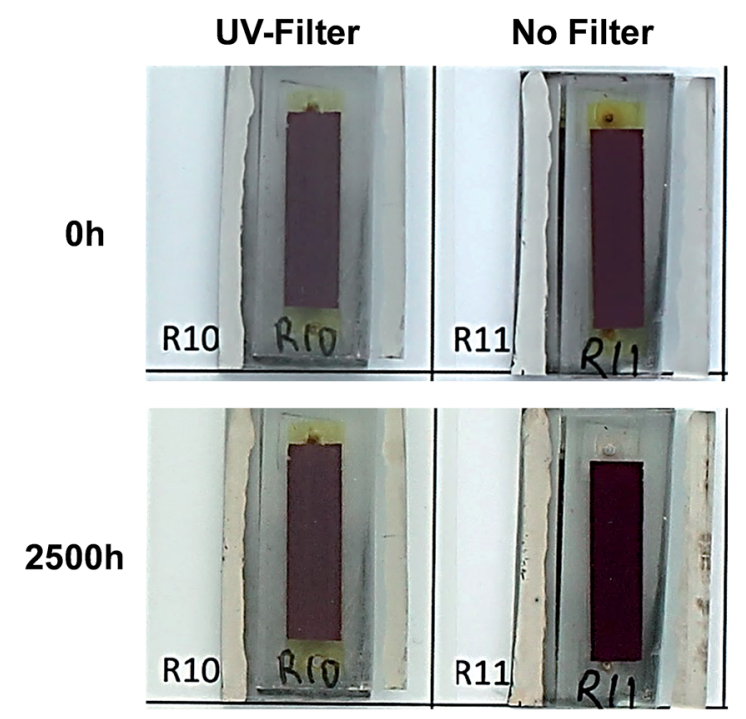

Fig. 4 (a) $\eta$ vs. time for N719-dyed DSC devices light-soaked under a Dyesol@ UPTS lamp $\left(400 \mathrm{~W} \mathrm{~m}^{-2}\right.$ ) either with (solid lines $\&$ circles) or without (dashed lines $\&$ crosses) a UV-filter. Devices were held under a $10 \Omega$ load (red lines), open (blue lines) or short circuit (green lines), (b) RGB pixel intensity data vs. time for electrolyte colour in devices without a UV filter and (c) device images. 
shows an increase in efficiency of open circuit cells at $200 \mathrm{~h}$ but not in the cells at short circuit or under load. This is due to the increase in efficiency from the stabilisation of the cells as they age. By comparison, the cells at short circuit show no efficiency increase which suggests degradation dominates for these devices. The cells at open circuit show very little degradation after $2500 \mathrm{~h}$ with a UV filter. It is important to note that when studying device degradation, the first component to fail is the one which determines the overall lifetime. For UV-filtered N719 devices, UV-vis analysis of the aged electrolyte shows that the $\mathrm{I}_{3}{ }^{-}$concentration is unchanged over $2500 \mathrm{~h}$ (ESI Fig. 12†). However, UV-vis analysis of N719 electrolyte without UV filtering confirms literature reports showing that $\mathrm{I}_{3}{ }^{-}$drops from $50 \mathrm{mM}$ to $20.7 \mathrm{mM}$, which validates the colour change shown by the image analysis data. However, $\mathrm{I}_{3}{ }^{-}$is still present which suggests the situation is more complex than a complete loss of the redox couple. Considering the different $I V$ parameters (ESI Fig. 17a $\dagger$ ), the $J_{\text {sc }}$ for UV-unfiltered N719 devices closely follows the overall efficiency suggesting this is the key factor affecting these devices. This is backed up by the $V_{\text {oc }}$ which shows a much more gradual drop over the $2500 \mathrm{~h}$ testing period whilst the FF actually increases for the UV-unfiltered devices between 500 and $1000 \mathrm{~h}$. This suggests that there is sufficient $\mathrm{I}_{3}{ }^{-}$remaining to support the photo-current in these devices. In support of these assertions, the $R_{\mathrm{sh}}$ and $R_{\mathrm{S}}$ data show relatively smaller changes until after $1000 \mathrm{~h}$ of testing (ESI Fig. 17b †). The $R_{\mathrm{sh}}$ increases for UV-filtered devices but not until after $1000 \mathrm{~h}$ whilst the $R_{\mathrm{S}}$ remains below $40 \Omega$ treatments except the UV-unfiltered, open circuit devices where $R_{\mathrm{S}}$ does reach $c a .70 \Omega$ beyond $2000 \mathrm{~h}$. However, none of the $R_{\mathrm{S}}$ values approach values anywhere close to the D35 devices which is in line with all the N719 devices still remaining operational even though some do drop to $\eta \sim 1.0 \%$. Mass spectrometry (ESI Fig. 18†) further verifies these data because the expected molecular ion for $\mathrm{N} 719$ dye $^{47}$ is still observed at $593.2450 \mathrm{amu}, z=2$ even after $2500 \mathrm{~h}$ of light soaking either with or without UV filtering confirming that fully operational N719 dye is still present in all devices. Thus, the observed N719 device failure is attributed to a combination of partial dye and redox couple degradation which his strongly influenced by UV exposure.

\section{Conclusions}

This work has shown that digital photography combined with RGB colour intensity analysis can be a powerful tool to study solar cell device lifetimes and potential degradation mechanisms (e.g. light harvester versus electrolyte). Because the method relies on digital photography and software-based data analysis, it is hugely versatile to both solar cell devices and device sub-components and indeed any sample, material or device that changes colour with time. It is also relatively low cost requiring only a routine SLR digital camera and a computer. The method is applicable at a wide range of length-scales from laboratory-scale devices $\left(c a .1 \mathrm{~cm}^{2}\right)$ to full modules $\left(e . g .1-2 \mathrm{~m}^{2}\right)$. In this context, the method can also be used to study large numbers of samples or devices simultaneously. In this paper, we have studied up to 21 DSC devices at a time but this method means that the main limitation on lifetime testing is the number of devices that can be manufactured rather than the testing method itself. In fact, the main limitation on the sample size or number of samples is the space required versus the camera focal length and spatial resolution. In reality, because very high pixel density digital cameras ( $>10$ mega-pixel) can routinely be purchased at low cost it is only really space that should limit image analysis. In addition, because the method is fully digitized, it can be easily automated to run on time-scales from seconds to years.

For solar cell devices, the main issues currently known to affect lifetimes are light, temperature and humidity exposure. We have shown that this imaging method can be applied to indoor or simulated light exposure and, with a weather-proof camera, it should also be suitable for outdoor testing with appropriate compensation for changing light intensities which can affect colour. It should also be possible to use digital imaging to monitor accelerated testing (e.g. very high light intensities and/or in combination with temperature and humidity). As such, the method has the potential to be developed as a testing standard for solar cells and modules. Finally, we have also shown that the method can be used to study degradation mitigation strategies (e.g. UV-sensitive electrolyte can be stabilised using a UV filter) to extend the DSC lifetimes by prolonging the life of device sub-components.

Thus, the colour of the dyed $\mathrm{TiO}_{2}$ has been shown to be an effective indicator of dye and/or electrolyte lifetime and these data have been corroborated by device performance data and $e x$ situ device analysis using IR, UV-vis and X-ray photoelectron spectroscopy as well as mass spectrometry. These data show that D35 dye degrades under light exposure in the presence of iodine electrolytes with or without UV filtering. However, for N719 devices, the dye and iodine-based electrolyte partially fail under UV exposure but UV filtering can successfully mitigate against this. Comparing data from both dyes suggests that open circuit is the most suitable device arrangement for degradation testing. Hence, in future, simple colour monitoring could be used for rapid screening of PV sub-component and device lifetimes.

\section{Acknowledgements}

We gratefully acknowledge funding from EPSRC CASE and Tata Steel (LF), the Welsh Government for Sêr Cymru (EWJ, PJH, RJH, RA) and NRN (CPK), EPSRC EP/M015254/1 (AC, JM), EPSRC/ InnovateUK EP/I019278/1 (JS), the EPSRC UK National Mass Spectrometry Facility at Swansea University and Pilkington-NSG for TEC ${ }^{\mathrm{TM}}$ glass.

\section{Notes and references}

1 B. O'Regan and M. Grätzel, Nature, 1991, 353, 737.

2 A. Hagfeldt, G. Boschloo, L. Sun, L. Kloo and H. Pettersson, Chem. Rev., 2010, 110, 6595.

3 A. Yella, C.-L. Mai, S. M. Zakeeruddin, S.-N. Chang, C.-H. Hsieh, C.-Y. Yeh and M. Grätzel, Angew. Chem., Int. Ed., 2014, 53, 2973. 
4 Z. Yao, M. Zhang, R. Li, L. Yang, Y. Qiao and P. Wang, Angew. Chem., Int. Ed., 2015, 54, 5994.

5 Z. Yao, M. Zhang, H. Wu, L. Yang, R. Li and P. Wang, J. Am. Chem. Soc., 2015, 137, 3799.

6 K. Kakiage, Y. Aoyama, T. Yano, K. Oya, T. Kyomen and M. Hanaya, Chem. Commun., 2015, 51, 6315.

7 K. Kakiage, Y. Aoyama, T. Yano, K. Oya, J. Fujisawa and M. Hanaya, Chem. Commun., 2015, 51, 15894.

8 A. Hinsch, J. M. Kroon, R. Kern, I. Uhlendorf, J. Holzbock, A. Meyer and J. Ferber, Progress in Photovoltaics: Research and Applications, 2001, 9, 425.

9 J. Kawakita, Science \& Technology Trends, 2010, 5, 70.

10 R. Harikisun and H. Disilvestro, Sol. Energy, 2011, 85, 1179. 11 M. Grätzel, C. R. Chim., 2006, 9, 578.

12 P. M. Sommeling, M. Späth, H. J. P. Smit, N. J. Bakker and J. M. Kroon, J. Photochem. Photobiol., A, 2004, 164, 137.

13 G. Xue, Y. Guo, T. Yu, J. Guan, X. Yu, J. Zhang, J. Liu and Z. Zou, Int. J. Electrochem. Sci., 2012, 7, 1496.

14 M. Giustini, D. Angelone, M. Parente, D. Dini, F. Decker, A. Lanuti, A. Reale, T. Brown and A. di Carlo, J. Appl. Electrochem., 2012, 43, 209.

15 T. Bessho, E. Yoneda, J.-H. Yum, M. Gugliemi, I. Tavernelli, H. Imai, U. Rothlisberger, M. K. Nazeeruddin and M. Grätzel, J. Am. Chem. Soc., 2009, 131, 5930.

16 S. Mastroianni, I. Asghar and K. Miettunen, Phys. Chem. Chem. Phys., 2014, 16, 6092.

17 T. Horiuchi, H. Miura and S. Uchida, Chem. Commun., 2003, 3036.

18 A. Connell, P. J. Holliman, M. L. Davies, C. D. Gwenin, S. Weiss, M. B. Pitak, P. N. Horton, S. J. Coles and G. Cooke, J. Mater. Chem. A, 2014, 2(11), 4055.

19 A. Connell, P. J. Holliman, E. W. Jones, L. Furnell, C. Kershaw, M. L. Davies, C. D. Gwenin, M. B. Pitak, S. J. Coles and G. Cooke, J. Mater. Chem. A, 2015, 3, 2883.

20 S. Hwang, J.-H. Lee, C. Park, H. Lee, C. Kim, C. Park, M.-H. Lee, W. Lee, J. Lee, K. Kim and C. Kim, Chem. Commun., 2007, 4887.

21 P. J. Holliman, M. Mohsen, A. Connell, M. L. Davies, K. AlSalihi, M. B. Pitak, G. J. Tizzard, S. J. Coles, R. W. Harrington, W. Clegg, C. Serpa, O. H. Fontes, C. Charbonneau and M. J. Carnie, J. Mater. Chem., 2012, 22(26), 13318.

22 D. Joly, L. Pellejà, S. Narbey, F. Oswald, J. Chiron, J. N. Clifford, E. Palomares and R. Demadrille, Sci. Rep., 2014, 4, 4033.

23 H. Tanaka, A. Takeichi, K. Higuchi, T. Motohiro, M. Takata, N. Hirota, J. Nakajima and T. Toyoda, Sol. Energy Mater. Sol. Cells, 2009, 93, 1143.

24 J. Gao, W. Yang, M. Pazoki, G. Boschloo and L. Kloo, J. Phys. Chem. C, 2015, 119, 24704.

25 A. Burke, L. Schmidt-Mende, S. Ito and M. Grätzel, Chem. Commun., 2007, 234.
26 T. Geiger, S. Kuster, J.-H. Yum, S.-J. Moon, M. K. Nazeeruddin, M. Grätzel and F. Nüesch, Adv. Funct. Mater., 2009, 19, 2720.

27 P. J. Holliman, M. L. Davies, A. Connell, B. Vaca Velasco and T. M. Watson, Chem. Commun., 2010, 46, 7256.

28 S. Paek, H. Choi, C. Kim, N. Cho, S. So, K. Song, M. K. Nazeeruddin and J. Ko, Chem. Commun., 2011, 47, 2874.

29 C. Qin, Y. Numata, S. Zhang, X. Yang, A. Islam, K. Zhang, H. Chen and L. Han, Adv. Funct. Mater., 2014, 24, 3059.

30 T. Wu, T. Lin, J. Zhao, H. Hidaka and N. Serpone, Environ. Sci. Technol., 1999, 33, 1379.

31 A. Fujishima, T. N. Rao and D. A. Tryk, J. Photochem. Photobiol., C, 2000, 1, 1.

32 C. Karunakaran and R. Dhanalakshmi, Sol. Energy Mater. Sol. Cells, 2008, 92, 1315.

33 M. Asghar, M. Kati, M. Simone, H. Janne, H. Vahlman and P. Lund, Sol. Energy, 2012, 86, 331.

34 D. P. Hagberg, X. Jiang, E. Gabrielsson, M. Linder, T. Mariando, T. Brinck, A. Hagfeldt and L. Sun, J. Mater. Chem., 2009, 19, 7232.

35 L. Yang, U. B. Cappel, E. L. Unger, M. Karlsson, K. M. Kalrsson, E. Gabrielsson, L. Sun, G. Boschloo, A. Hagfeldt and E. M. J. Johansson, Phys. Chem. Chem. Phys., 2012, 14, 779.

36 T. Watson, P. Holliman and D. Worsley, J. Mater. Chem., 2011, 21, 4321.

37 P. J. Holliman, K. J. Al-Salihi, A. Connell, M. L. Davies, E. W. Jones and D. A. Worsley, RSC Adv., 2014, 4(5), 2515.

38 H. Hofer, J. Carroll, J. Neitz, M. Neitz and D. R. Williams, J. Neurosci., 2005, 25, 9669.

39 F. Nour-Mohhamadi, S. D. Nguyen, G. Boschloo, A. Hagfeldt and T. Lund, J. Phys. Chem. B, 2005, 109, 22413.

40 H. T. Nguyen, H. M. Ta and T. Lund, Sol. Energy Mater. Sol. Cells, 2007, 91, 1934.

41 E. Leonardi, S. Penna, T. M. Brown, A. Di Carlo and A. Reale, J. Non-Cryst. Solids, 2010, 356, 2049.

42 M. Carnie, D. Bryant, T. Watson and D. Worsley, Int. J. Photoenergy, 2012, 1.

43 L. Han, N. Koide, Y. Chiba, A. Islam and T. Mitate, C. $R$. Chim., 2006, 9, 645.

44 H. Ellis, V. Leandri, A. Hagfeldt, G. Boschloo, J. Bergquist and D. Shevchenko, J. Mass Spectrom., 2015, 50, 734.

45 NIST, X-ray Photoelectron Spectroscopy Database, Version 4.1, National Institute of Standards and Technology, Gaithersburg, 2012, http://srdata.nist.gov/xps/.

46 S. Yu, S. Ahmadi, P. Palmgren, F. Hennies, M. Zuleta and M. Göthelid, J. Phys. Chem. C, 2009, 113, 13765.

47 R. Buscaino, C. Baiocchi, C. Barolo, C. Medana, M. Grätzel, M. K. Nazeeruddin and G. Viscardi, Inorg. Chim. Acta, 2008, 361, 798. 